\title{
Physical activity of women over 60 - methodology of activity measurement
}

\author{
Angelika Cisek-Woźniak ${ }^{1, A-D \oplus}$, Kinga Mruczyk ${ }^{1, F}{ }^{\oplus}$, Rafał W. Wójciak ${ }^{1,2, E \oplus ~}$ \\ ${ }^{1}$ Department of Dietetics, Faculty of Physical Culture in Gorzów Wlkp., Poznan University of Physical Education, Gorzów \\ Wielkopolski, Poland \\ ${ }^{2}$ Department of Clinical Psychology, University of Medical Sciences, Poznań, Poland \\ $A$ - Research concept and design, B - Collection and/or assembly of data, C - Data analysis and interpretation, \\ $D$ - Writing the article, E-Critical revision of the article, F- Final approval of article
}

Cisek-Woźniak A, Mruczyk K, Wójciak RW. Physical activity of women over 60 - methodology of activity measurement. Ann Agric Environ Med. 2022; 29(1): 86-93. doi: 10.26444/aaem/133760

\begin{abstract}
Introduction. Physical activity has a positive effect on health. The level of physical activity changes with age. Elderly people often reduce their physical activity, among other things, due to deteriorating health or the belief that it is inappropriate to indulge in sports or be physically active at old agge. On the other hand, the lack of systematic physical activity in the elderly can lead to a reduction in the body's efficiency in many health aspects. Although there are many methods of measuring human physical activity, there is no ideal tool for measuring that activity.

Objective. The main aim of the study was to assess the effectiveness of the use of selected methods of measuring physical activity in the elderly, as well as to evaluate the influence of the measured activity on the nutritional status of women over 60 years of age.

Materials and method. The study was carried out in the area of western Poland in a group of 110 generally healthy women above the age of 60 , who were divided into 3 groups of intensity of undertaken physical activity (low active $30.00 \%$, moderately active $41.82 \%$ and active $28.18 \%$ ). A pedometer and a physical activity diary were used to measure physical activity. Body composition was assessed by the bioelectrical impedance method which uses a body composition analyzer. Body height and weight, lean mass of limbs and body, adipose tissue content, total water content, waist circumference to hip circumference (WHR), and BMI (Body Mass Index) were assessed.

Results. The correlation coefficient between the methods of assessing physical activity, i.e. the number of minutes/day and the number of steps/day, was 0.92 and was statistically significant at the level of $p<0.001$. This was assumed to be a strict correlation. Based on the physical activity diary, it was estimated that women spent an average of 92.85 minutes a day on physical activity, while the data obtained from the pedometer showed that they performed an average of 4,462 steps a day. The average age of the respondents was 67.25 years, and average BMI $-28.07 \mathrm{~kg} / \mathrm{m}^{2}$.

Conclusion. A close correlation was demonstrated between the applied methods for assessing physical activity shows about the appropriate selection of methods, as well as, due to their ease of use, their use to assess physical activity in the elderly.
\end{abstract}

\section{Key words}

physical activity, older people, pedometer, questionnaire, physical activity factor, women health

\section{INTRODUCTION}

The ageing of the population is one of the most important challenges in health and social policy worldwide. As a result of the ageing process, several physiological changes occur in the human body: muscle mass and lean body mass decrease, and regular exercise is unable to prevent the decline in muscle strength, although it does permit a longer maintenance of fitness and independence. Currently, it is commonly believed that physical activity can significantly modify the progressive, albeit natural, ageing process[1].

Physical activity, defined as any form of body movement caused by muscle contractions, in which energy expenditure exceeds resting energy levels, benefits the health of people of all ages. This definition covers all forms of physical activity, i.e. recreational physical activity, professional sports, physical activity in and around the home, and physical activity related

Address for correspondence: Angelika Cisek-Woźniak, Department of Morphological and Health Sciences, Dietetic Division, Faculty of Physical Culture, Poznań University of Physical Education, 13 Estkowskiego, 66-400 Gorzów Wielkopolski, Poland E-mail: a.cisek@awf-gorzow.edu.pl

Received: 09.12.2020; accepted: 28.02.2021; first published: 23.03.2021 to transport [2]. The lack of systematic physical activity in the elderly may lead to a reduction in the body's efficiency in many health aspects. One of the conditions for successful ageing is independence. The percentage of disabled people increases with age, both in terms of performing complex and basic everyday activities. The main risk factors for disability, not related to the disease process, include low physical activity, smoking and a high BMI [3].

The ageing process leads to disturbances in the functioning of tests on controls, including traffic routes $[4,5]$. At the same time, physical activity is an important factor affecting the general condition of the elderly and reducing mortality. [6].

Physical activity of the elderly affects their vitality, maintaining muscle strength, balance, flexibility, endurance [7], and thus maintaining physical fitness, independence in everyday life, maintaining the quality of life $[8,9]$, as well as many organs and systems, and on metabolism $[10,11]$.

Physically active people have a lower risk of obesity by maintaining a healthy body weight and physical activity also has a positive effect on their emotional state, and are able to assess their health better [12]. Despite the beneficial effects of physical activity on health, research shows that most adults of 
all ages spend their leisure time passively [13]. Furthermore, the elderly reduce their physical activity, among others, as a result of deteriorating health or the misconception that it is not appropriate to indulge in sports with ageing [14]. Systematic physical activity results in numerous physical and mental benefits for the human body at any age. It allows the reduction of risk factors for many diseases, in particular those related to the cardiovascular system and metabolic diseases. Lack of physical activity is now a serious social problem, requiring wide-ranging intervention not only of health care, especially of people dealing with health promotion, but also of other sectors of public activity. The effects of physical activity depend on its type, volume, intensity and regularity. Individual measurement of physical activity allows not only the indirect assessment the state of human health and the risk of cardiovascular or metabolic diseases. It is a tool which enables the formulation detailed recommendations of physical activity for each individual, taking into account the data obtained in the initial study. However, there is no ideal tool for measuring human motor activity [15].

There are many methods for measuring human physical activity, each one of chich has its own advantages and disadvantages. These methods can be divided into objective and subjective. Two types of objective methods can be distinguished: the first are those that use a metabolic criterion for measurements, such as the level of oxygen uptake, the carbon dioxide released, or heat. All measurements using objective methods allow determination of the energy expenditure of the body. The type of objective method involves indirect methods, i.e. those in which special meters are used for measurement: accelerometers, heart rate meters and pedometers, chich allow kinematic analysis, such as motion detection and recording, [16].

The subjective methods of assessing human motor activity include a diagnostic survey, with the use of questionnaires carried out by the interviewer or by the respondents themselves (as a form of self-assessment). The subjective methods also include multimedia equipment (tape recorders, cameras) and writing journals. As mentioned above, no method is perfect. Of course, some methods are considered the "gold standard", such as the double-labelled water method in indirect calorimetry. Nevertheless, each has its own advantages (such as accuracy of measurement, ease of use, possibility of use in the entire population, possibility of measurement at home and over a longer period of time, the ability to measure a single motor activity and can be divided into small, medium and high physical activity), and disadvantages (such as no actual energy expenditure is measured, measurement based only on the subjective interpretation of the tested person, possible lack of regularity, shocks measured as steps, the high cost of measurement, or the presence of an expert for the analysis [17].

Several instruments are available to measure physical ativity in older adults, such as questionnaires, diaries, accelerometers and pedometers. Although several aspects (e.g., strengths, weaknesses and practical considerations) have to be considered when selecting an instrument [18], questionnaires appear to be popular for the measurement of physical activity in older adults [19]. In contrast to accelerometers, they are usually feasible in large epidemiological studies and wellaccepted by participants. For example, questionnaires are used in large national surveys to determine and compare levels of physical activity among different countries [20].
The use of the same measurement method in these surveys facilitates comparability among physical activity estimates [21]. The choice of the method depends on the age of the tested person, type of tests, hardware capabilities, cooperation with the person, at which we measure, and for this study.

Taking into account the above, and primarily concerning the research group, as well as financial opportunities and hardware, two methods of measurement were selected to assess the motor activity of women in this study. Objective method - measurement with a pedometer, and subjective method - assessment based on a physical activity diary. The obtained data obtained were to show the practical applications of the selected methods in everyday life for independent programming of physical activity, especially among the elderly.

A pedometer is a simple, electronic device used to count steps, it allows the monitoring of physical activity throughout the day (even during the simplest walks) by calculating the number of steps taken by a person during the day, or at other specified times. The operation of pedometers is based on the use of a pendulum that captures the movements of the human body, both accelerating and slowing down the speed of movement while moving. They allow the evaluation of various physical activities. These devices are not perfect, but they are cheap to use and easy to use by the elderly [22].

The physical activity diary is a simple, cheap method of assessing physical activity, it is not burdensome for the subject and does not change behaviour. It is a descriptive method conducted by the subject within the course of motor activity.

The study aimed to find an adequate tool for assessing physical activity, as well as ass assessing the impact of this activity on the nutritional status of women over 60 years of age.

\section{MATERIALS AND METHOD}

The study group consisted of 110 generally healthy women from western Poland. The following qualification criteria were adopted: gender - women, age - over 60, functional status - independence in carrying out everyday activities and in good general health. All participants, after being provided with written information about the study, gave written consent to participate. The average age in the studied target group was $67.25 \pm 6.10$ years, height $158.76 \pm 5.77 \mathrm{~cm}$, and body weight $70.57 \pm 11.30 \mathrm{~kg}$.

The study procedure was reviewed and approved by the Bioethics Committee of the Medical University in Poznań (Decision No. 184/18 of 01/02/2018). All study participants gave their written informed consent. All procedures were carried out according to the ethical standards of the Helsinki Declaration of 1975.

Diagnostic tests were carried out in the study group: scientific (movement) tests using two independent measurement methods: pedometer and activation (movement) diary. The women were assessed using the Bioelectrical Impedance Analysis (BIA) method with the use of the Tanita Body Composition Analyzer (BC 420 MA). Body height and weight, lean body mass, adipose tissue content, total water content, waist circumference index (WHR) and Body Mass Index (BMI) were assessed. Participant characteristics are listed in Table 1.

Physical activity was measured by two independent simultaneously applied methods. The first is to measure the number of steps with the GARMIN Forerunner $35 \mathrm{HR}$ sports 
Table 1. Characteristics of the study group

\begin{tabular}{|c|c|c|}
\hline Variable & Unit & $\begin{array}{c}\text { Total } \\
(n=110)\end{array}$ \\
\hline & & $\begin{array}{c}\text { arithmetic average } \pm S D \\
\text { median } \\
\text { (min-max) } \\
\text { 90th }\end{array}$ \\
\hline Age & years & $\begin{array}{c}67.25 \pm 6.10 \\
67.00(60.00-91.00) \\
74.00\end{array}$ \\
\hline Body height & $\mathrm{cm}$ & $\begin{array}{c}158.76 \pm 5.77 \\
159.00(144.00-176.00) \\
165.00\end{array}$ \\
\hline Body mass & $\mathrm{kg}$ & $\begin{array}{c}70.57 \pm 11.30 \\
68.70(50.20-100.00) \\
86.27\end{array}$ \\
\hline BMI & $\mathrm{kg} / \mathrm{m}^{2}$ & $\begin{array}{c}28.07 \pm 4.76 \\
27.35(18.40-42.50) \\
35.00\end{array}$ \\
\hline WHR & [waist/hip circumference] & $\begin{array}{c}0.88 \pm 0.088 \\
0.87(0.68-1.160) \\
0.99\end{array}$ \\
\hline FAT & $\mathrm{kg}$ & $\begin{array}{c}26.29 \pm 8.48 \\
24.90(9.40-51.10) \\
38.33\end{array}$ \\
\hline FFM & $\mathrm{kg}$ & $\begin{array}{c}44.08 \pm 4.60 \\
43.85(28.20-54.90) \\
50.12\end{array}$ \\
\hline TBW & $\mathrm{kg}$ & $\begin{array}{c}32.27 \pm 3.36 \\
32.10(20.60-40.20) \\
36.71\end{array}$ \\
\hline
\end{tabular}

Values are expressed as means \pm standard deviations $-\mathrm{SD}$; medians - Me; ranges - min-max BMI - body mass index; FAT - fat mass; FFM - fat-free mass; TBW - total body water content.

watch, equipped with a step counter. Each person was required to wear the watch on the wrist of their left hand permanently for three days, excluding bedtime and before contact with water (bathing, swimming, exercising in water). The second method is the assessment of physical activity using an activity diary, in which the participants of the study recorded for the same three days the type of activity they performer, and how many minutes they spent on the activity. Organized sports activities, such as gymnastics, fitness, swimming, dancing, tenis and Nordic walking were taken into account, as well as other physical activities, such as gardening, cycling and intense walking. Physical activity was classified based on the number of steps taken during three days, measured with a pedometer-watch, and the number of minutes indicated in the physical activity diary, which participants also completed for three days. The following were adopted as measurable units: the number of steps per day (data obtained from the pedometer) and the number of minutes per day spent on physical activity (data from the diary).

Participants were also asked not to change the activity undertaken by recording and wearing the device during the registration days. The obtained resultsprovided the basis for calculating the physical activity index, which indicated the number of steps taken per minute (steps/minutes). The bioelectrical impedance (BIA) method was used to assess the body composition of the subjects. The tests were performed using the Tanita BC 420 MA body composition analyzer (Tanita Co., Japan). The measurement was performed after a light meal in the morning. Before taking the body composition measurement, body height was measured with each person stepping on to the scales barefoot, keeping still, with the upper limbs lowered and not touching the thighs.

The collected results were statistically analyzed using the STATISTICA 13 statistical package. For all variables (parameters of general characteristics, physical activity, body composition), arithmetic means, median, minimum and maximum value, standard deviations and the 90th percentile were calculated. A comparative analysis of the studied features within selected groups and the assessment of relationships between them were based on non-parametric procedures due to deviations of the measured characteristics from the normal distribution (Mann-Whitney test, Spearman correlation). The interaction between the selected features was assessed using ANOVA. In the case of the survey data, the Pearson chi-square test was used and the obtained results were presented in percentage terms. The $\mathrm{p}<0.05$ level was considered statistically significant.

\section{RESULTS}

The average age of the respondents was 67.25 years, and the average BMI $-28.07 \mathrm{~kg} / \mathrm{m}^{2}$. Measurements showed that the women took an average of 4,462 steps a day (Fig. 1), and spent an average of $92.85 \pm 53.05$ minutes a day on physical activity (Fig. 2). The minimum number of steps was 746.00 and the

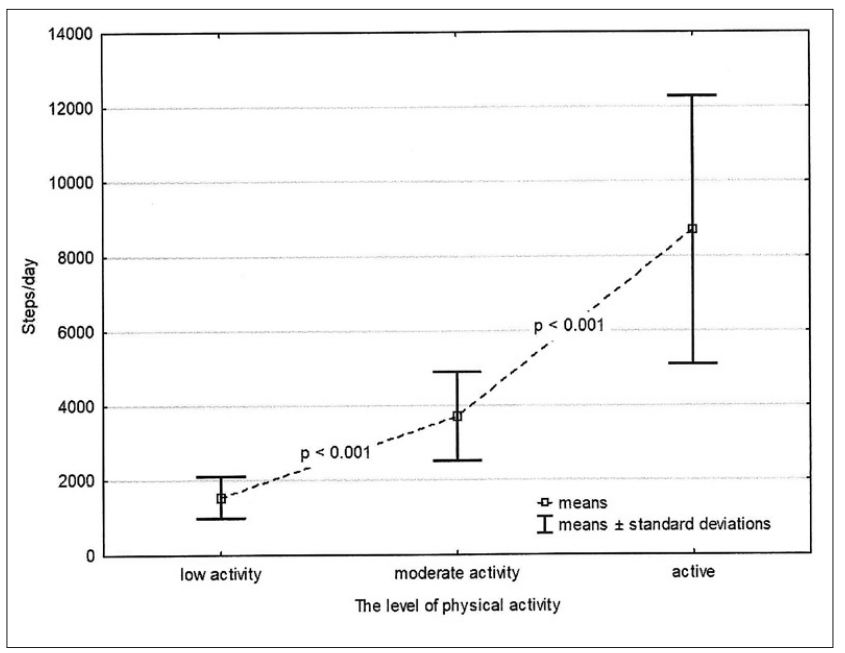

Figure 1. Physical activity (steps/day) in three groups of tested women

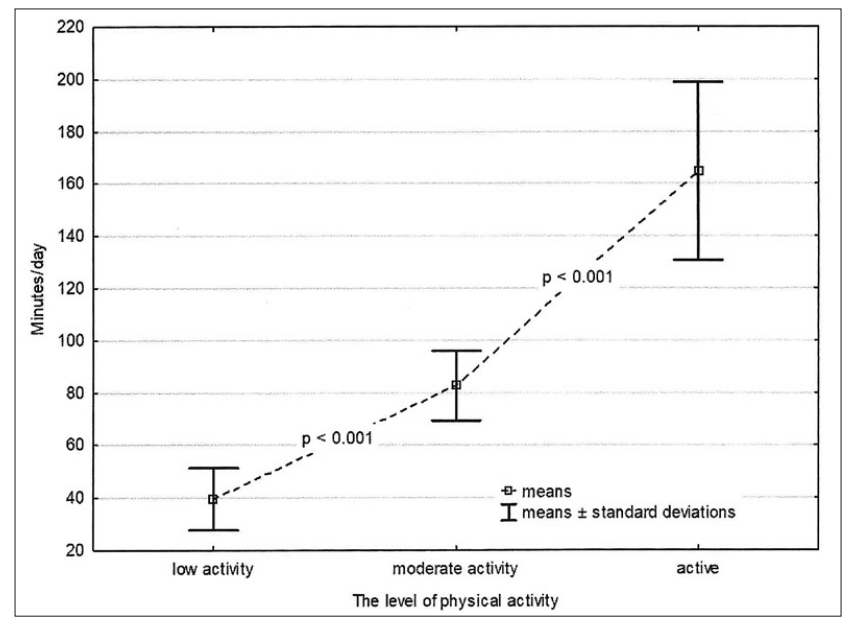

Figure 2. Physical activity (minutes/day) in three groups of tested women 
maximum - 16,750.00. The minimum number of minutes of activity was 14.29 and the maximum number -240.00 .

The Pearson correlation coefficient (the data met the condition of a normal distribution Shapiro-Wilk test) between the measurement methods used (steps/day and minutes/ day) was 0.92 , and was statistically significant at the level of $\mathrm{p}<0.001$, which can be taken as a strict correlation (Fig. 3). The obtained results of measurements gave the basis for the division of women into three groups according to specific physical activity: low activity, moderate and active $30.00 \%$, $41.82 \%$ and $28.18 \%$, respectively) (Tab. 2). The division into three comparative groups was made using the k-means cluster analysis, the variables based on which the above-mentioned groups of active women were distinguished, and the activity undertaken is steps/day and min/day.

Group 1 consisted of 33 women (30.00\% of the general study group) who, compared to the entire group, had the lowest activity results in steps/day ( $\mathrm{Min}=746.00 ; \mathrm{Max}=2,550.00)$ and in minutes/day (Min=14.29; $\mathrm{Max}=57.14)$. Group 2 was the most numerous group - 46 women $(41.82 \%$ of the study group), which was characterized by medium and high activity in steps/day (Min=2,100.00; $\mathrm{Max}=7,083.33)$ and in minutes/day (Min=61.43; Max=112.14). Group 3 consisted of 31 women with final and average activity scores in steps/ day (Min=3,700.00; $M a x=16,750.00)$, and in minutes/day (Min=120.00; $\operatorname{Max}=240.00)$.

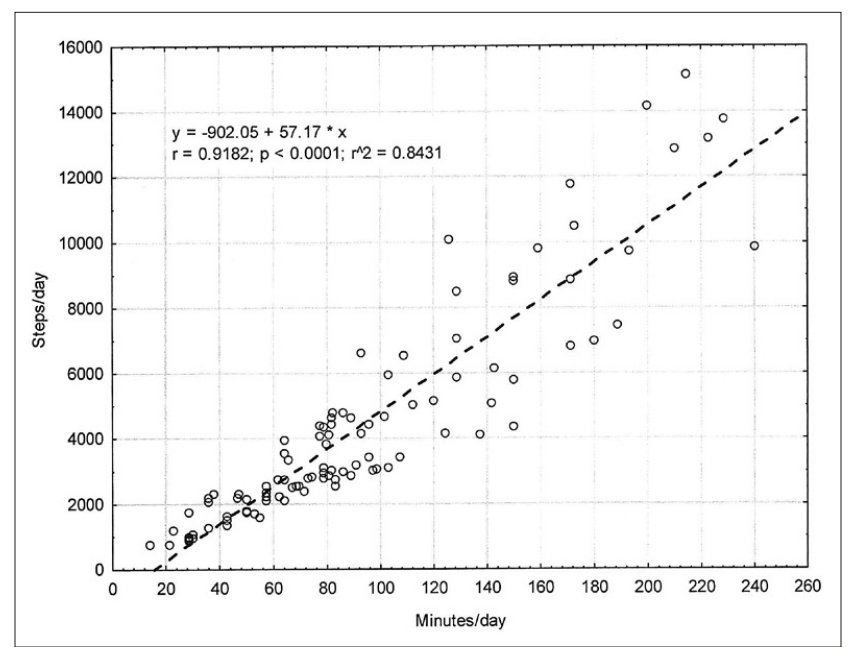

Figure 3. Relationship between the number of steps and duration of physical activity in one day in the surveyed women

The average value of the BMI index for the general study group was $28.07 \pm 4.76$, with the value $\mathrm{Min}=18.40$ and $\operatorname{Max}=42.50$, while the average value of the WHR index was $0.88 \pm 0.09(\mathrm{Min}=0.68, \mathrm{Max}=1.16)$. In the individual groups of women, the average value of the BMI index decreased with the increase in the level of physical activity, similar to the

Table 2. Characteristic of physical activity of participants

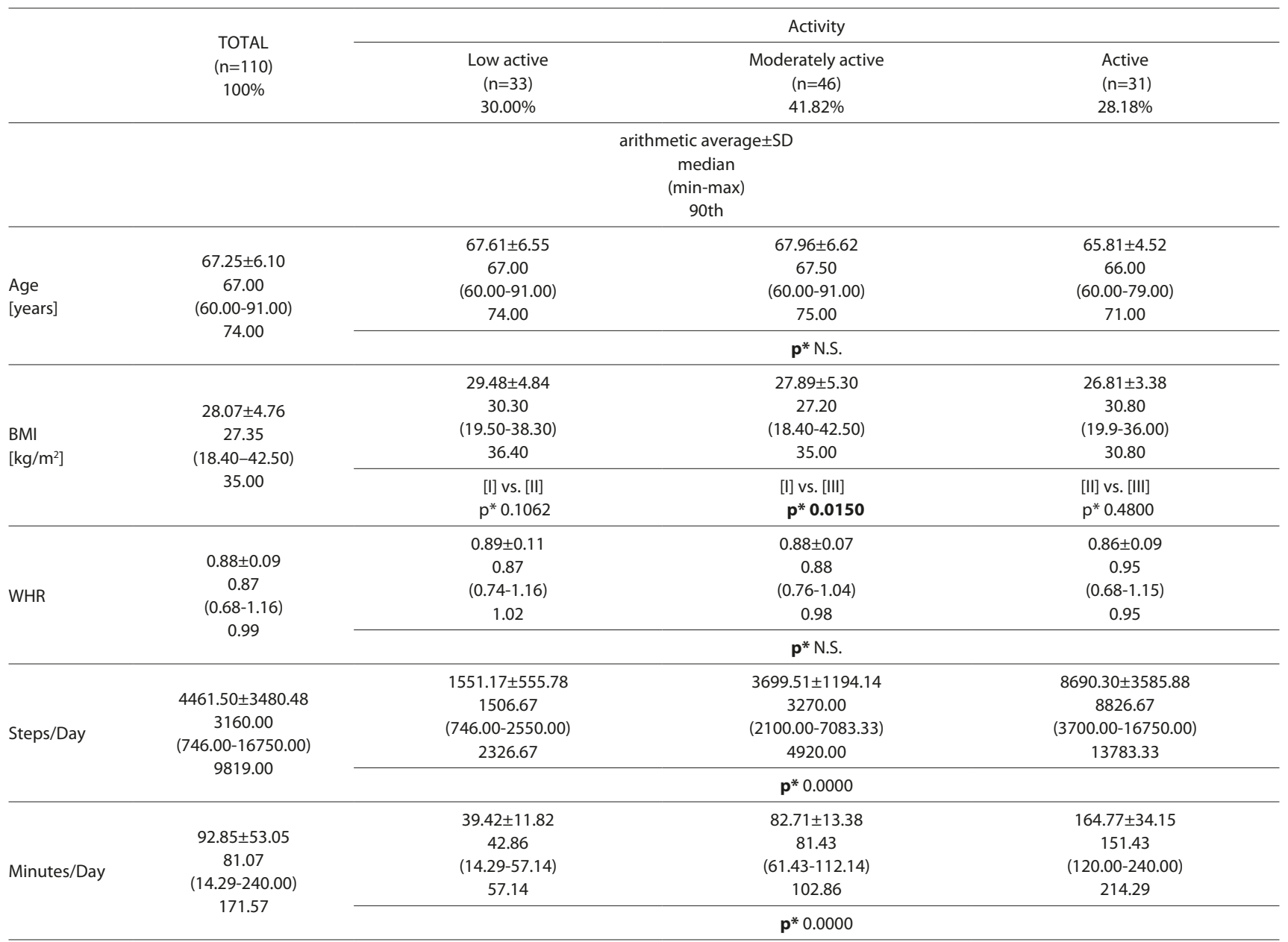

$\mathrm{p}^{*}$ (significance level of $\mathrm{p}$ differences) Mann-Whitney test. Measurement results in the studied groups differed from the normal distribution (verified using the Shapiro-Wilk test); therefore, the Mann-Whitney test was used to compare them. Statistical significance is shown in bold. 
value of the WHR index. The lowest values of these indicators were observed in group 3 who obtained the mean BMI $26.81 \pm 3.38(\mathrm{Min}=19.90, \mathrm{Max}=36.00)$ and WHR $0.86 \pm 0.09$ $(\mathrm{Min}=0.68, \operatorname{Max}=1.15)($ Tab. 2). In the descriptive statistics programme, such a division is absolutely correct, and the active position differed significantly from the rest of the respondents. Concerning the above data, the Mann-Whitney $\mathrm{U}$ test verified that the obtained groups differ significantly from each other. Figure 4 shows the relationship between the individual levels of physical activity and BMI values.

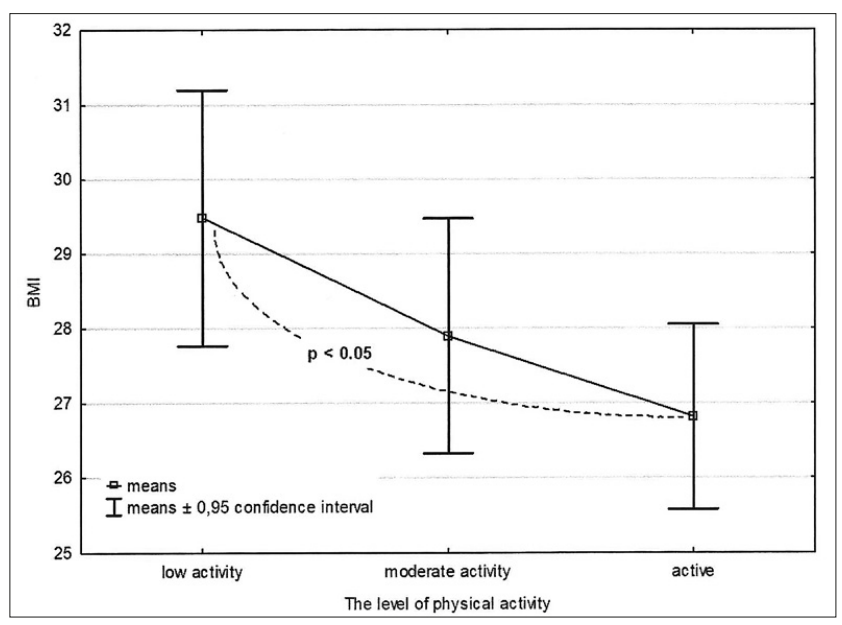

Figure 4. Physical activity and BMI

Table 3 presents the division of the respondents according to age categories $(<65 ; 66-70 ;>70)$ and physical activity (low active, moderately active, active), which allows analysis of the examined features, assuming comparable features in the groups ( $\mathrm{chi}=2.8947 ; \mathrm{p}>0.05)$. The most numerous group of active women were those $<65$ years of age $(46-41.82 \%)$. In the age range of $66-70$, there were 39 women (35.45\%), while in the $>70$ years of age group there were 25 women $(22.73 \%)$.

Table 3 . Number of people in the compared groups by age and physical activity

\begin{tabular}{|c|c|c|c|c|c|}
\hline \multirow{2}{*}{$\begin{array}{l}\text { Chi }^{2}=2,8947 \\
p=0.5756\end{array}$} & \multirow{2}{*}{ Activity level } & \multicolumn{4}{|c|}{ Age range } \\
\hline & & $<65$ & $(66-70)$ & $>70$ & Total \\
\hline Number & \multirow{3}{*}{ Low active } & 12 & 6.12 & 9 & 33 \\
\hline$\%$ from the line & & $36.36 \%$ & $33.6 \%$ & $27.27 \%$ & $100.00 \%$ \\
\hline$\%$ of the total & & $10.91 \%$ & $10.91 \%$ & $8.18 \%$ & $30.00 \%$ \\
\hline Number & \multirow{3}{*}{ Moderately active } & 20 & 14 & 12 & 46 \\
\hline$\%$ from the line & & $43.48 \%$ & $30.43 \%$ & $26.09 \%$ & $100.00 \%$ \\
\hline$\%$ from the total & & $18.18 \%$ & $12.73 \%$ & $10.91 \%$ & $41.82 \%$ \\
\hline Number & \multirow{3}{*}{ Active } & 14 & 13 & 4 & 31 \\
\hline$\%$ from the line & & $45.16 \%$ & $41.94 \%$ & $12.90 \%$ & $100.00 \%$ \\
\hline$\%$ from the total & & $12.73 \%$ & $11.82 \%$ & $3.64 \%$ & $28.18 \%$ \\
\hline Number & \multirow{2}{*}{ Total activity } & 46 & 39 & 25 & 110 \\
\hline$\%$ from the total & & $41.82 \%$ & $35.45 \%$ & $22.73 \%$ & $100.00 \%$ \\
\hline
\end{tabular}

In the group of women with low physical activity, the lowest number of women were over 70 years of age (9-27.27\%), while in the age groups $<65,66-70,>70$ years, the number was the same (12-36.36\%). In the moderately active group, the number in the age groups decreased with age, i.e. the highest number were women aged $<65(20-43.48 \%), 66-70$ years of age $(14-30.43 \%)>70$ years of age $(12-26.09 \%)$. Similarly, in the group with the highest activity, the number in individual age groups decreased with age, i.e. 14 (45.16\%), 13 (41.94\%) and $4(12.90 \%)$, respectively. Younger women showed a greater level of physical activity, which decreased with increasing age of the surveyed women.

Table 4 presents physical activity (steps/day and minutes/ day) and the BMI value in individual age groups, assuming the age groups of participants established above $(<65,66-70$, $>70$ years). In age groups I and II ( $<65$ and $66-70$ years), the levels of physical activity did not differ significantly, but these groups were the most active. In the oldest age group, the average levels of physical activity were the lowest, although it was in this group that the maximum value of minutes/day was found. The value of the BMI index increased with the age of the study participants. Nevertheless, the BMI value for the entire study group was $28.07 \pm 4.76\left[\mathrm{~m}^{2} / \mathrm{kg}\right]$ wchich, according to the standards, indicates that the whole group was overweight.

In terms of the value of the physical activity, as well as the value of BMI, significant statistical differences $(<0.05)$ were observed between age groups I and II, as well as II and III. Physical activity in the three age groups of the surveyed women is illustrated in Figure 5 (minutes/day) and Figure 6 (steps/day). Table 5 presents the value of physical activity

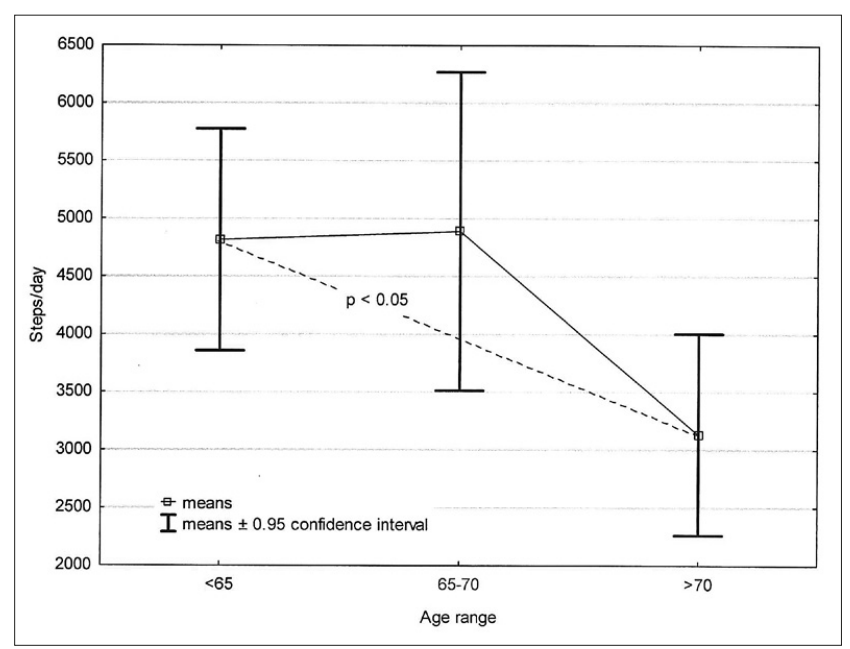

Figure 5. Physical activity (steps/day) in three age groups of the surveyed women

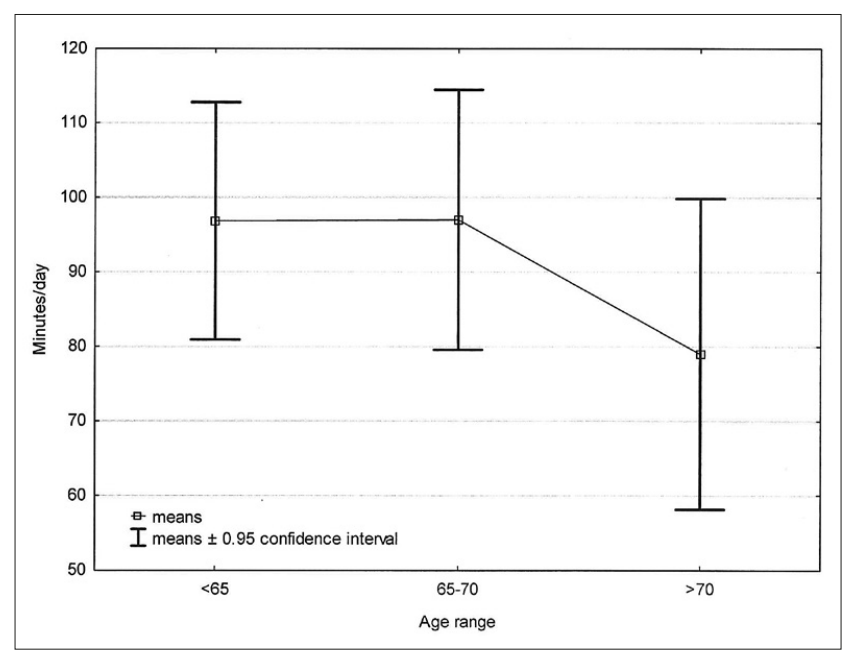

Figure 6. Physical activity (minutes/day) in three age groups of the surveyed women 
Table 4. Activity factor and Body Mass Index (BMI) index in individual age groups of the surveyed women

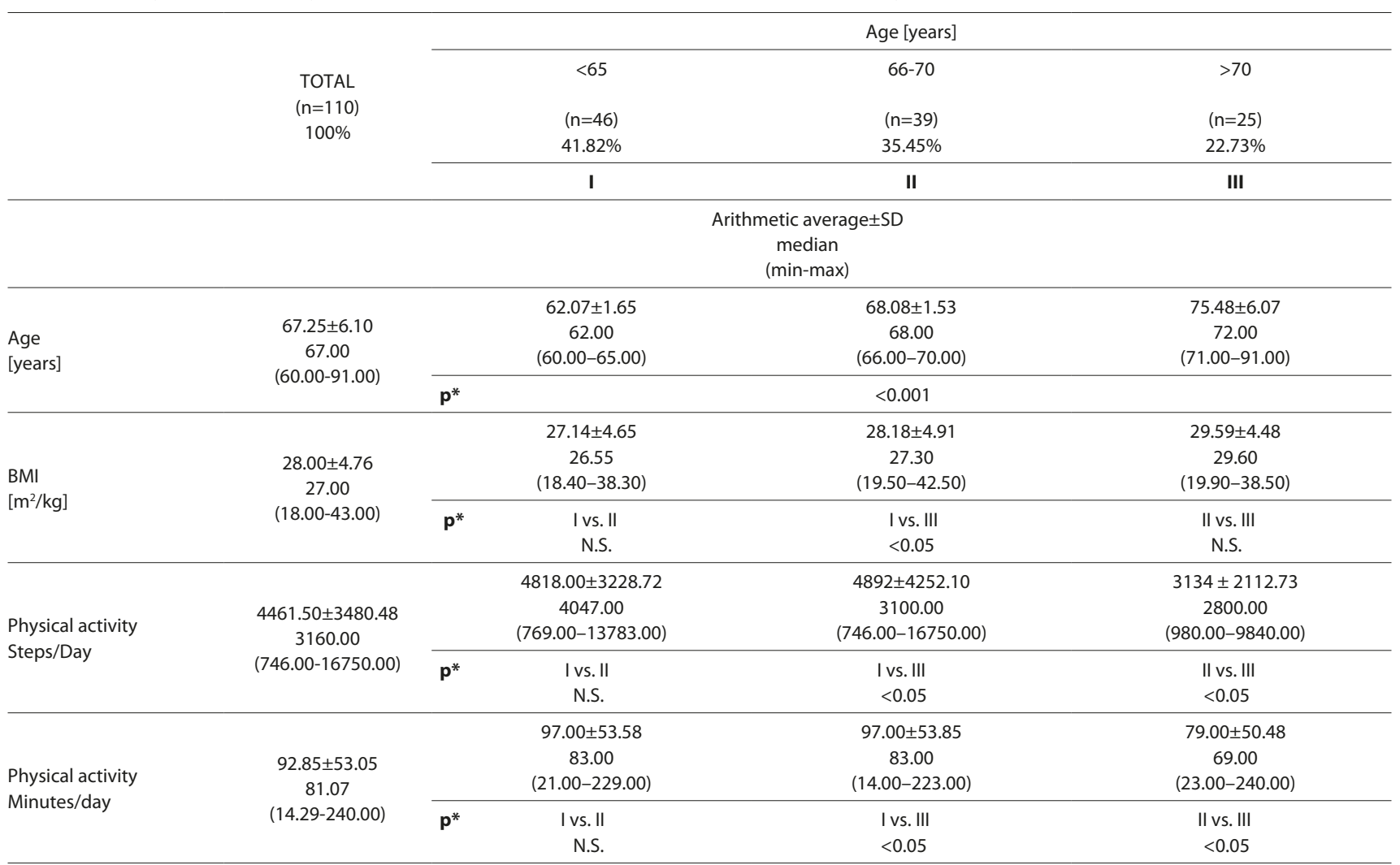

$\mathrm{p}^{*}($ significance level of $\mathrm{p}$ differences)

Table 5. Activity factor and overall body composition

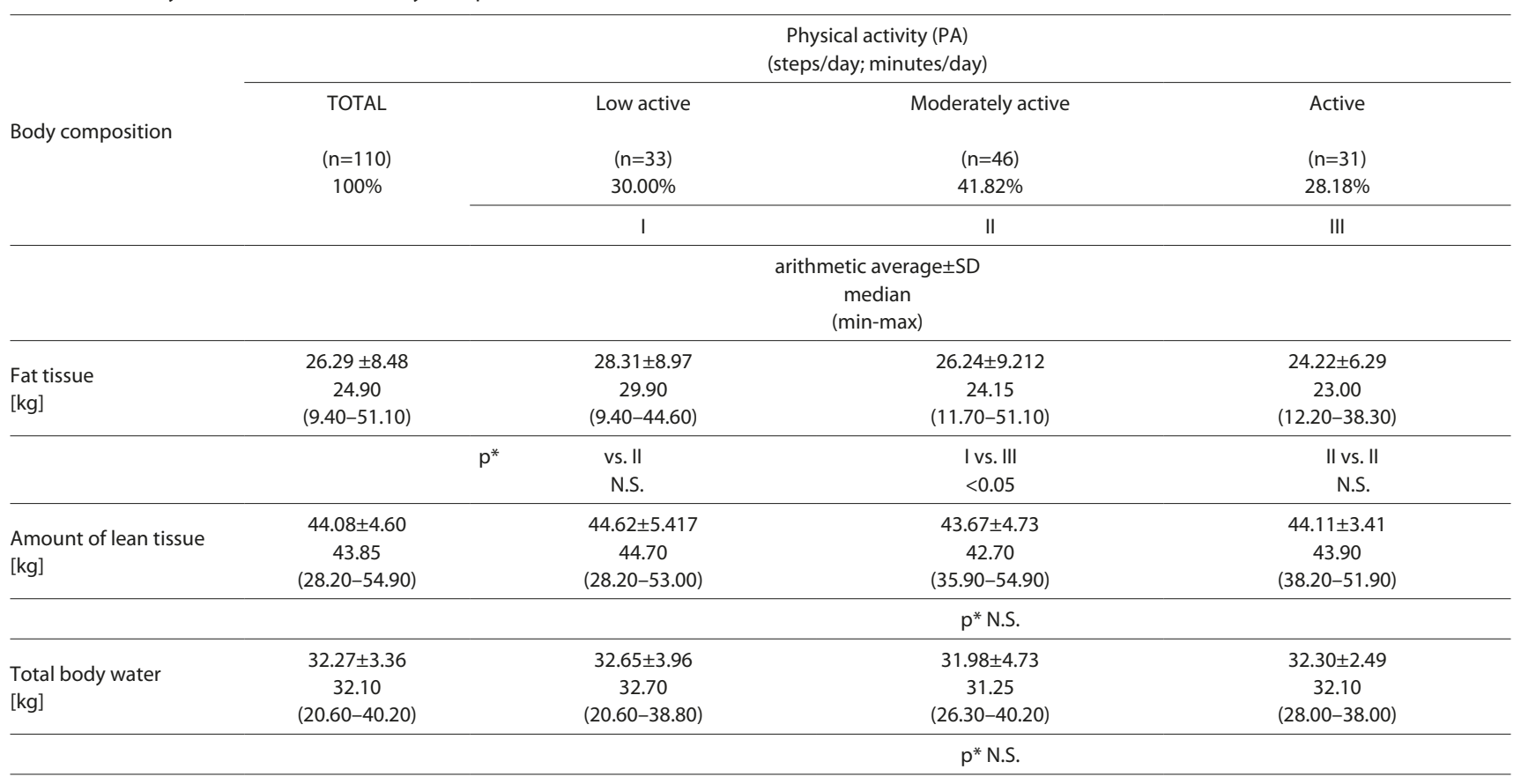

p* significance level of differences

(steps/day and minutes/day) in the particular activity of group III (low active, moderately active and active) concerning the general body composition of the studied women (adipose tissue, lean tissue and water content). The content of adipose tissue was the lowest in the group of the most active women $(24.22 \pm 6.29 \mathrm{~kg})$, While it was the highest in the group of women with the lowest physical activity $(28.31 \pm 8.97 \mathrm{~kg})$. Significant statistical differences $(<0.05)$ were observed between activity groups I and III. No significant statistical differences were observed concerning the other values of body composition. 


\section{DISCUSSION}

In the presened study, two methods were used to assess the physical activity of womenaged over 60: measurement with a sports watch with a pedometer function, and based on data collected from participants in the form of a completed diary of physical activity. The literature on the subject describes many studies in which a pedometer was used as the tool for measuring physical activity. In a study by Mizuno et al., a pedometer was used to measure physical activity and energy expenditure during walking and jogging. Comparing the energy expenditure values obtained from the pedometer with the energy expenditure calculated based on the $\mathrm{VO}^{2} \mathrm{max}$ relationship, it was found that the pedometer is a reliable tool for measuring energy expenditure on physical activity [9]. Similarly, in a study by Nielson et al., conducted on a group of 100 people (men and women), it was found that the pedometer is a good tool for measuring physical activity and energy expenditure, especially moderate-intensity physical activity [23]. In the current study, energy expenditure was not measured with a pedometer, but by the number of steps measured, which provided the basis for estimating the level of the women's physical activity. However, it should be remembered that the correct measurement of physical activity with a pedometer requires wearing the device for some length time. Kubot's research has shown that for proper measurement, a pedometer should be worn for a minimum of three days to obtain a real measurement of physical activity [12]. In the current study, the women also wore pedometers for three days.

Similarly, a diary can be a tool to assess the physical activity of the elderly. This method was used by CisekWoźniak et al. to assess the physical activity of 100 women aged 60 - 75 years, who were asked to complete a selfcreated questionnaire regarding their physical activity. The participants were asked about the number of minutes they spend on organized physical activity, such as fitness, walking, dancing, swimming, and other form sof physical activity. The obtained answers provided the authors of the study the basis for dividing the respondents into three groups of physical activity: high, medium and lack (respectively 30.00, 49.00, $21.00 \%)$. The division was based on the weekly time spent in physical activity by older women: high physical activity - over 60 minutes a week, average - below 50 minutes a week, the most active women - 120 minutes a week on exercise [11].

The authors of the study 'Adherence to physical activity guidelines and functional fitness of elderly women, using objective measurement' by A. Nawrock et al., in by Brovold T. et al., Gouveia ER et al. or Bergier J. who surveyed the respondents of their research with subjective methods, i.e. with the use of questionnaires. The research showed that elderly people who started exercising recommended parameters, significantly influenced their health and functional efficiency [24].

Physical activity is assessed most often based on interviews obtained from the subjects $[21,25]$; however, in the case of older people, objective measurement Rusing various types of devices seems to be better for assessing energy expenditure related to physical activity [15]. At the same time, there are relatively few studies of elderly people assessing actual physical activity and related energy expenditure. Of course, some studies use the double-labelled water method or indirect calorimetry, but the measurements with these methods are burdensome for the participants $[26,27,28]$.
This presented study also proves the influence of physical activity on the nutritional status and body composition of people undertaking physical activity. The women differed between the groups in the value of the BMI index, the average value of which for the entire study group indicates overweight [29]; however, on analyzing its values in the individual activity groups, it decreases with increasing physical activity. Moreover, significant statistical differences between the groups with the lowest and the highest physical activity may indicate the influence of this activity on the BMI index, and thus on overweight and obesity. Literature data indicate the positive effect of physical (exercise) activity on the correct bodyweight and the value of BMI [30,31], which is also confirmed in this study.

The above can be supplemented by the WHR values obtained in individual groups of physical activity, which indicate the presence of abdominal obesity; however, these values fluctuate at the lower limit adopted for women (0.85). In the group of women with the highest activity, this value was closest to the limit of 0.85 , with the lowest WHR values indicating no obesity (0.68) in this group.

Analyzing the content of adipose tissue that women had in individual activity groups, it can be clearly stated that physical activity had a decisive influence on its amount in the body of the examined women. The content of body fat decreased with increasing levels of physical activity. Visible differences in the values of this body component can be observed in the group of women with the lowest physical activity compared to the women with the highest activity. Such findings are confirmed in the extensive world literature $[32,33,34]$.

Research on the assessment of the development, usefulness and effectiveness in facilitating pro-health activities is neither wide nor very advanced [35]; however, health devices and applications seem to be an interesting element for promoting pro-health behaviour. By providing their users with convenient, quick and clear access to data on the current basic health parameters, as well as monitoring changes in these values over time, they increase health self-awareness, giving the opportunity to set and monitor progress in achieving goals and improve self-control, at the same time strongly motivating toimplementation of pro-health actions [36].

\section{CONCLUSIONS}

The presented study attempted to answer the question: can a pedometer and a diary of recorded physical activity be tools for measuring and assessing the physical activity of the elderly, and how this activity affects nutritional status and body composition. The following final observations (conclusions) arose:

- The methods used (pedometer and diary) are adequate tools for assessing the level of physical activity of the elderly, which is indicated by the calculated correlation coefficient at the level of close correlation. These methods can be a determinant for the assessment of physical activity and can be used to measure and programme the daily selfphysical activity of the elderly.

- The observed statistical differences between the values of the level of physical activity and the values of the BMI index or the content of adipose tissue in the groups with the highest and the lowest physical activity, may indicate 
the appropriate application of measurement methods. The value of the BMI index increased with age in the group of respondents. The presence of physical activity in the lifestyle of women over the age of 60 showed a protective effect against the increase in the value of the BMI index and the body fat.

- Age gradually limits the physical activity of women. In the study group, it was shown that physical activity decreased with age. Younger people showed higher physical activity.

- The largest percentage of the study group were women with a moderate level of physical activity.

- The unfavourable distribution of adipose tissue occurred mainly in the least physically active women and, at the same time, the oldest, which may pose an increased risk of disease and deterioration of health.

The conducted study indicates the need for education and implementation of disease prevention programmes related to the need to implement physical activity and overweight among older women.

\section{REFERENCES}

1. Siparsky PN, Kirkendall DT, Garrett E. Muscle Changes in Aging. Understanding Sarcopenia Sports Health. 2014; 6(1): 36-40. https:// doi.org/10.1177/1941738113502296

2. Didace N, Eun-Kyung K. Measurement Methods for Physical Activity and Energy Expenditure. Review. Clin Nutr Res. 2017; 6(2): 68-80. http://doi: 10.7762/cnr.2017.6.2.68

3. Włodarek D, Majkowski M, Majkowska L, Aktywność fizyczna starszych osób mieszkających w gminie Koprzywnica. Rocz Panstw Zakl Hig. 2012; 63(1): 111-117. PubMed.

4. Park SH, Han KS, Kang CB. Effects of exercise programs on depressive symptoms, quality of life, and self-esteem in older people: A systematic review of randomized controlled trials. Appl Nurs Res. 2014; 27: 219-26. https://doi.org/10.1016/j.apnr.2014.01.004

5. Germain CM, Batsis JA, Vasquez E, et al. Muscle strenght, physical activity, and functional limitations in older with central obesity. J Aging Res. 2016; 83873249(5). http://dx.doi.org/10.1155/2016/8387324

6. Górniak M, Rybakowski J. The effect of physical activity on psychiatric disturbances. Farmakoter Psychiat Neurol. 2015; 31: 113-119.

7. Wojtasik W, Szulc A, Kołodziejczyk, et al. Wybrane zagadnienia dotyczące wpływu wysiłku fizycznego na organizm człowieka. J Edu Health Sport. 2015; 5: 350-372.

8. Gronek P, Wielinski D, Cyganski P, et al. Review of Exercise as Medicine in Cardiovascular Disease: Pathology and Mechanism. Aging and Disease. 2020;11:2. http://dx.doi.org/10.14336/AD.2019.0516

9. Mizuno C, Yoshida T, Udo M. Estimation of energy expenditure during walking and jogging by using an electropedometer. Ann Physiol Anthropol. 1990; 9(3): 283-289.

10. Sertel M, Arslan SA, Kurtoglu F, et al. Physical activity, depression and quality of life in aging proces. Biomed Res. 2017; 28(9): 4165-4170.

11. Cisek-Woźniak A, Mruczyk K, Wójciak RW. Physical activity and dietary supplementation intake among postmenopausal women. Balt Health Phys Act. 2019; 11(3): 66-7. https://doi:10.29359/BJHPA.11.3.07

12. Kim J, Noh J-W, Park J, Kwon YD. Body Mass Index and Depressive Symptoms in Older Adults: A Cross-Lagged Panel Analysis. PLoS One. 2014; 9(12): 1-9. doi: 10.1371/journal.phone.0114891

13. Mutz M, Reimers AM, Demetriou Y. Leserem Time Sports Activities and Life Satisfaction: Deeper Insights Based on a Representative Survey from Germany. Applied Research in Quality of Life. 2020; 9. https:// doi.org/10.1007/s11482-020-09866

14. Sabia S, van Hees VT, Shipley MJ, et al. Association between questionnaire and accelerometer-assessed physical activity: the role of sociodemographic factors. Am J Epidemiol. 2014; 179: 781-90.

15. Lipert A, Jegier A. Metody pomiaru aktywności ruchowej człowieka. Polish J Sport Med 2009; 3(6); Vol. 25: 155-168.
16. Sylvia GL, Bernstein EE, Hubbard JL, et al. Practical Guide to Measuring Physical Activity, J Acade Nutr Diet. 2014; 114: 2: 199-208 https://doi. org/10.1016/j.jand.2013.09.018

17. Hidding LM, Chinapaw MJM, van Poppel MNM, et al. An updated systematic review of childhood physical activity questionnaires. Sports Med. 2018; 48: 2797-842. https://doi.org/10.1007/s4027 9-018-0987-0

18. Hupin D, Roche F, Gremeaux V, et al. Even a low-dose of moderate-tovigorous physical activity reduces mortality by $22 \%$ in adults aged $\geq 60$ years: a systematic review and meta-analysis. Br J Sports Med. 2015; 49 : 1262-7. https://doi.org/10.1136/bjsports-2014-094306

19. Falck RS, McDonald SM, Beets MW, et. al. Measurement of physical activity in older adult interventions: a systematic review. Br J Sports Med. 2016; 50: 464-70. https://doi.org/10.1136/bjsports 2014-094413

20. Guthold R, Stevens GA, Riley LM, et al. Worldwide trends in insufficient physical activity from 2001 to 2016: a pooled analysis of 358 populationbased surveys with 1.9 million participants. Lancet Glob Health. 2018; 6: e1077-86. https://doi.org/10.1016/S2214-109X(18)30357-7

21. Loyen A, van Hecke L, Verloigne M, et al. Variation in population levels of physical activity in European adults according to cross-European studies: a systematic literature review within DEDIPAC. Int J Behav Nutr Phys Act. 2016; 13: 72. https://doi.org/10.1186/s12966-016-0398-2

22. Alarie N, Kent L. Physical Activity Assessment and Impact. Diet and Exercise in Cystic Fibrosis 2015; 299-306. https://doi.org/10.1016/ B978-0-12-800051-9.00034-1

23. Nielson R, Vehrs PR, Fellingham GW, et al. Stepcounts and energy expenditure as estimated by pedometry during treadmill walking at differentstride frequencies. J Phys Act Health 2011; 8(7): 1004-1013. doi: 10.1123/jpah.8.7.1004

24. Nawrocka A, Młynarski W, Cholewa J. Adherence to physical activity guidelines and functional fitness of elderly women, using objective measurement. Ann Agric Environ Med. 2017; 24(4): 632-635. doi: https://doi.org/10.5604/12321966.1231388

25. Westerterp KR. Doubly labelled water assessment of energy expenditure: principle, practice, and promise. Eur J Appl Physiol. 2017; 117(7): 12771285. http://doi:10.1007/s00421-017-3641-x

26. Skender S, Ose J, Chang-Claude J, et al. Accelerometry and physical activity questionnaires - a systematic review. BMC Public Health. 2016; 16: 515. https://doi.org/10.1186/s12889-016-3172-0

27. Silsbury Z, Goldsmith R, Rushton A. Systematic review of the measurement properties of self-report physical activity questionnaires in healthy adult populations. BMJ Open. 2015; 5: e008430. https://doi. org/10.1136/bmjop en-2015-008430

28. Sabia S, van Hees VT, Shipley MJ, et al. Association between questionnaireand accelerometer-assessed physical activity: the role of sociodemographic factors. Am J Epidemiol. 2014; 179: 781-90.

29. Nuttall FQ. Body Mass Index. Obesity, BMI, and Health: A Critical Review. Nutr Today. 2015; 50(3): 117-128. http://doi:10.1097/ NT.0000000000000092

30. Pandey A, LaMonte M, Klein L, et al. Relationship Between Physical Activity, Body Mass Index, and Risk of Heart Failure. J Am Coll Cardiol. 2017; 69(9): 1129-1142. http://dx.doi.org /10.1016/j.jacc.2016.11

31. Jackson C, Herber-Gast GC, Brown W. Joint Effects of Physical Activity and BMI on Risk of Hypertension in Women: A Longitudinal Study. 2014, Article ID 271532, 7 pages http://dx.doi.org/10.1155/2014/271532

32. Janiszewska R, Orawiec R, Nowak S. Assessment of body composition, total fatness and fatty tissue distribution in women during process of aging. Probl Hig Epidemiol. 2015; 96(2): 517-522.

33. Yokoyama K, Yamada Y, Akamatsu Y. Effects of Capsinoids on Daily Physical Activity, Body Composition and Cold Hypersensitivity in Middle-Aged and Older Adults: A Randomized Study. Nutrients 2020; 12(1): 212. https://doi.org/10.3390/nu12010212

34. Telford RM, Telford RD, Cochrane T, et al. The influence of sport club participation on physical activity, fitness and body fat during childhood and adolescence: The LOOK Longitudinal Study. J Sci Med Sport. 2016; 19: 400-406.

35. Falck RS, McDonald SM, Beets MW, et al. Measurment of physical acyivity in older adult interventions: a systematic review. Br J Sports Med. 2016; 50: 464-70. https://doi.org/10.1136/bjsports-2014-094413

36. Kowalski K, Rhodes R, Naylor P-J, et al. Direct and indirect measurement of physical activity in older adults: a systematic review of the literature. Int J Behav Nutr Phys Act. 2012; 9: 148. https://doi. org/10.1186/1479-5868-9-148 